\title{
Minimally invasive transthoracic device closure of isolated ventricular septal defects without cardiopulmonary bypass: Long-term follow-up results
}

\author{
Quansheng Xing, MD, ${ }^{\mathrm{a}}$ Qin Wu, MD, ${ }^{\mathrm{a}}$ Lei Shi, MB, ${ }^{\mathrm{b}}$ Yuhan Xing, MB, ${ }^{\mathrm{c}}$ and Guiling Yu, MS ${ }^{\mathrm{b}}$
}

Objective: Minimally invasive transthoracic device closure (MITDC) of ventricular septal defects (VSD) under transesophageal echocardiography guidance is increasingly and successfully being performed with excellent results. We retrospectively reviewed 458 patients who received this treatment in our center and summarized the 6-year follow-up results.

Methods: From March 2007 to March 2013, 458 patients (mean age, $11.41 \pm 6.73$ months; body weight, $9.82 \pm 5.88 \mathrm{~kg}$ ) underwent MITDC. Patients were strictly followed up according to a standard protocol by 2 specially appointed doctors. Meanwhile, 283 cases with an isolated VSD who underwent traditional surgical repair during this period were also reviewed and several characteristics were compared between the 2 groups.

Results: A total of 441 cases were successfully closed $(96.29 \%)$, and the other 17 patients were converted to surgical closure. There were no deaths or major complications. Concentric devices were used in 313 cases $(70.98 \%)$, eccentric devices in 113 cases $(25.62 \%)$, and special devices in 15 cases $(3.40 \%)$. The mean intracardiac deployment time was $18.35 \pm 17.13$ minutes (3-48 minutes). Most of the patients were discharged within 5 days after surgery. Follow-up in 426 patients $(96.60 \%)$ ranged from 6 to 78 months $(47.31 \pm 19.69$ months) and revealed no severe complications. Fewer minor complications, such as device-related trace to mild tricuspid regurgitation, residual shunt, and right bundle branch block, occurred with MITDC than surgical closure.

Conclusions: MITDC of a VSD on a beating heart is a safe and effective alternative to conventional treatments. The 6-year clinical outcomes are promising. Modification of occluders and the delivery set play an important role in good outcomes. (J Thorac Cardiovasc Surg 2015;149:257-65)

See related commentary on pages $265-6$.

Ventricular septal defect (VSD) is the most common congenital heart defect. Both surgical and percutaneous device closure of VSDs have drawbacks and limitations. In 2007, Xing and colleagues ${ }^{1}$ reported successful minimally invasive transthoracic device closure (MITDC) of 11 perimembranous VSDs with a newly designed delivery system under transesophageal echocardiography (TEE) guidance. Since then, MITDC of VSDs under TEE guidance has been increasingly and successfully performed

\footnotetext{
From the Divisions of Cardiothoracic Surgery ${ }^{\mathrm{a}}$ and Cardiology, ${ }^{\mathrm{b}}$ Heart Center, Qingdao Women and Children's Hospital, Qingdao University, Qingdao, China; Department of Epidemiology, ${ }^{\mathrm{c}}$ No.1 Clinical Medical College, Chongqing Medical University, Chongqing, China.

Disclosures: Authors have nothing to disclose with regard to commercial support. All authors contributed equally.

Read at the 94th Annual Meeting of The American Association for Thoracic Surgery, Toronto, Ontario, Canada, April 26-30, 2014.

Received for publication April 5, 2014; revisions received June 24, 2014; accepted for publication July 20, 2014; available ahead of print Aug 27, 2014

Address for reprints: Quansheng Xing, MD, Qingdao Women and Children's Hospital, Qingdao University, Qingdao, Shandong, China (E-mail: xingqs0532@ 126.com).

$0022-5223 / \$ 36.00$

Copyright (c) 2015 by The American Association for Thoracic Surgery

http://dx.doi.org/10.1016/j.jtcvs.2014.07.078
}

with excellent preliminary and midterm results in China and in some European countries. ${ }^{2-13}$

We retrospectively reviewed 458 patients with a VSD who received this treatment and 283 patients with a VSD who underwent traditional surgical repair from 2007 to 2013 at our center. The 6-year clinical follow-up results were summarized and compared between the 2 groups.

\section{PATIENTS AND METHODS \\ Patients}

Patients were selected according to the surgical indications for an isolated VSD: refractory heart failure with medication; repeated respiratory infection ( $>6$ times per year); tardiness of body development; evidence of left heart volume overload (heart enlargement observed on chest radiographs, left atrium/aorta ratio $>1.5$ on echocardiography, left ventricular end diastolic diameter $>2$ standard deviations on echocardiography); and a history of previous endocarditis. Exclusion criteria for MITDC were nonrestrictive or malaligned VSD; those with inlet extension of the VSD; VSD with significant aortic prolapse; a newborn infant or young infant with large VSD and severe pulmonary hypertension; those who could not be followed up; and patients or their guardians who refused to accept this new treatment.

Between March 2007 and March 2013, 458 patients with a VSD underwent off-pump MITDC. The study was approved by the institutional review board. Individual informed consent was obtained from the patients'guardians. During the same period, a total of 283 patients with an isolated VSD underwent surgical closure with cardiopulmonary bypass (CPB), including 197 patients not fit for MITDC, 69 patients whose guardians refused to accept this new 


\section{Abbreviations and Acronyms \\ $\mathrm{cAVB}=$ complete atrioventricular block \\ $\mathrm{CPB}=$ cardiopulmonary bypass \\ ECG = electrocardiography \\ IVS = interventricular septum \\ MITDC $=$ minimally invasive transthoracic device closure \\ PDA $=$ patent ductus arteriosus \\ TEE $=$ transesophageal echocardiography \\ $\mathrm{TR}=$ tricuspid regurgitation \\ TTE $=$ transthoracic echocardiography \\ VSD $=$ ventricular septal defect}

treatment, and 17 patients converted to heart surgery from failed MITDC. The patients' general characteristics are listed in Table 1.

\section{Devices and Delivery Sets}

The occluder was modified from the Amplatzer (AGA Medical Corporation, Plymouth, Minn) atrial septal defect and membranous VSD occluder, made by Lifetech Scientific (Shenzhen) Co Ltd (Shenzhen, China) and Shanghai Shape Memory Alloy Co Ltd (Shanghai, China). The size of the device corresponds to the waist dimension of the device. Five types of occluders were supplied in this cohort: a perimembranous VSD concentric occluder (concentric), a perimembranous VSD eccentric occluder (eccentric), a muscular VSD occluder (muscular), a patent ductus arteriosus (PDA) occluder, and a special occluder (saddlelike) for subarterial VSD (Figure 1). The device is available in sizes ranging from 4 to $16 \mathrm{~mm}$ in 1-mm increments (Figure 2). The waist height of each type of occluder ranged from $3 \mathrm{~mm}$ to $7 \mathrm{~mm}$ in $1-\mathrm{mm}$ increments (Figure 3).

The device size was chosen according to the position and diameter of the VSD, and the thickness of the interventricular septum (IVS). We recommended a device with a waist size 1 to $2 \mathrm{~mm}$ larger than the diameter of the VSD and a waist height corresponding to the thickness of the IVS; a concentric occluder for a perimembranous VSD with a margin more than $2 \mathrm{~mm}$ from the aortic valve; an eccentric occluder for a perimembranous VSD with a margin less than $2 \mathrm{~mm}$ from the aortic valve; a muscular or PDA occluder for muscular VSD; a saddlelike occluder for subarterial VSD with less than mild aortic prolapse and regurgitation.

The entire delivery set was modified by Dr Quansheng Xing, ${ }^{5}$ including a trocar (Terumo Corporation, Tokyo, Japan), a flexible guidewire (SCW Medicath Ltd, Shenzhen, China), and a dilator, a delivery sheath, a delivery cable, and a loading sheath (Lifetech Scientific [Shenzhen] Co Ltd and Shanghai Shape Memory Alloy Co Ltd). The total length of the delivery set ranged from 20 to $30 \mathrm{~cm}$. The size of the delivery sheath selected depended on the device size (5F, 7F, or 9F).

\section{Procedure}

MITDC was performed under general anesthesia and TEE guidance in the operating room. The position, shape, size of the VSD and adjacent structures, especially its relationship with the aortic valve, were reassessed with TEE before operating and then the appropriate device and delivery system were selected. Access was through a small subxiphoid incision or the third left intercostal space beside the sternum for subarterial VSDs (Figure 4). A small pericardiotomy was performed and the pericardium was cradled to expose the free wall of the right ventricle. The detailed implanting steps of this technique were basically the same as described previously (Figure 5). ${ }^{5,7,9}$ If severe, arrhythmialike, frequent premature ventricular contractions, left bundle branch block, complete atrioventricular block (cAVB), failure to pass the guidewire through the VSD or implant the occluder, anything more than mild residual shunt, new aortic insufficiency, or more than mild tricuspid regurgitation (TR) was identified, the patients were converted to conventional repair with CPB. All patients with successful device closure were monitored in the intensive care unit until extubation, and urinalysis was performed daily for 3 days to exclude hemolysis. Anticoagulation therapy with aspirin ( $3 \mathrm{mg} / \mathrm{kg} / \mathrm{d}$ by mouth) was prescribed for 3 to 6 months. A total of 283 patients with isolated VSDs underwent conventional intracardiac surgery with $\mathrm{CPB}$ as routine.

\section{Follow-up}

Electrocardiography (ECG), transthoracic echocardiography (TTE), and chest radiography were performed before discharge. If needed, 24-hour electrocardiographic Holter monitoring was performed. Outpatient follow-up was at 1 month, 3 months, 6 months, 1 year, and annually and included clinical examination, ECG, TTE, and chest radiography. All patients were strictly followed up with the same standard protocol by 2 doctors who were specially appointed. Several characteristics (eg, operating time, complications, blood transfusion, hospital stay time, cost of hospitalization, and postoperative complications) were compared between the 2 groups.

\section{Data Analysis}

All continuous variables are expressed as means \pm standard deviation with a range, and nominal variables are presented as frequencies and percentages. Analysis of continuous variables was done with the Student $t$ test and analysis of categorical variables was performed with the $\chi^{2}$ test. SPSS 18.0 for Windows (SPSS Inc, Chicago, Ill) was used for statistical analysis.

\section{RESULTS}

\section{Procedure Data and Early Postoperative Results}

In the device closure group, VSDs were successfully closed in 441 patients $(96.29 \%)$, and the other 17 patients were converted to surgical closure, including 5 patients with moderate aortic insufficiency, 4 patients with residual shunts more than $2 \mathrm{~mm}$ wide or blood flow velocity more than $3.0 \mathrm{~m} / \mathrm{s}$ on TEE, 2 patients with severe arrhythmia occurring immediately after the guidewire was passed through the defect or occluder was deployed, 2 patients with right ventricle outflow tract obstruction with a pressure gradient more than $20 \mathrm{~mm} \mathrm{Hg}, 2$ patients in whom the guidewire failed to cross the defect, and 2 patients with abnormal occluder plasticity. A subxiphoid approach was used in 358 patients $(81.18 \%)$ and incision through the third left intercostal space beside the sternum was used in 83 patients $(18.82 \%)$. A concentric device was used in 313 patients $(70.98 \%)$, an eccentric device in 113 patients $(25.62 \%)$, and others in 15 patients $(3.40 \%)$; the others included 8 muscular devices, 5 saddlelike devices, and 3 PDA devices (1 patient with a central muscular VSD and an apical muscular VSD was closed with a muscular device and a PDA device, respectively). The mean size of the device used was $6.53 \pm 5.25 \mathrm{~mm}$ (range, $4-12 \mathrm{~mm}$ ). It was necessary to open more than 1 device for a given patient in 49 cases $(11.11 \%)$. In a 3-month-old baby girl, who weighed $5 \mathrm{~kg}$, a series of 6 occluders were used to close a 
TABLE 1. Preoperative baseline characteristics of patients undergoing transthoracic device or surgical closure of isolated ventricular septal defects

\begin{tabular}{|c|c|c|c|}
\hline Characteristic & Transthoracic device closure & Surgical closure & $P$ value \\
\hline Number & 458 & 283 & \\
\hline \multicolumn{4}{|l|}{ Gender, n $(\%)$} \\
\hline Male & $241(52.62)$ & $152(53.71)$ & .773 \\
\hline Female & $217(47.38)$ & $131(46.29)$ & \\
\hline Age, mo $\pm \mathrm{SD}$ (range) & $11.41 \pm 6.73(3-21)$ & $10.32 \pm 8.57(2-23)$ & .118 \\
\hline Body weight, $\mathrm{kg} \pm \mathrm{SD}$ (range) & $9.82 \pm 5.88(4.5-15)$ & $8.56 \pm 7.79(4-19)$ & .305 \\
\hline \multicolumn{4}{|l|}{ Chest radiograph } \\
\hline Cardiothoracic ratio, $\pm \mathrm{SD}$ (range) & $0.53 \pm 0.15(0.47-0.61)$ & $0.56 \pm 0.19(0.49-0.63)$ & .276 \\
\hline \multicolumn{4}{|l|}{ Electrocardiography, n (\%) } \\
\hline iRBBB & $25(5.46)$ & $19(6.71)$ & .482 \\
\hline iLBBB & $1(0.22)$ & 0 & .437 \\
\hline cRBBB & $4(0.87)$ & $9(3.18)$ & .432 \\
\hline \multicolumn{4}{|l|}{ Echocardiography } \\
\hline VSD size, $\mathrm{mm} \pm \mathrm{SD}$ (range) & $5.21 \pm 2.95(3-10)$ & $6.83 \pm 3.75(3-12)$ & .081 \\
\hline \multicolumn{4}{|l|}{ VSD location, $\mathrm{n}(\%)$} \\
\hline Perimembranous & $412(89.96)$ & $232(81.9)$ & .002 \\
\hline Subarterial & $40(8.73)$ & $47(16.61)$ & .001 \\
\hline Muscular & $6(1.31)$ & $4(1.41)$ & .906 \\
\hline Trace to mild TR, $\mathrm{n}(\%)$ & $39(8.52)$ & $53(18.73)$ & .000 \\
\hline $\mathrm{AR}, \mathrm{n}(\%)$ & $8(1.75)$ & $15(5.30)$ & .007 \\
\hline LVEF, $\% \pm \mathrm{SD}$ (range) & $63.33 \pm 13.85(58-76)$ & $58.30 \pm 11.96(52-68)$ & .197 \\
\hline LV-RV gradient, $\mathrm{mm} \mathrm{Hg} \pm \mathrm{SD}$ (range) & $55.37 \pm 12.81(41-69)$ & $38.27 \pm 21.42(12-56)$ & .031 \\
\hline
\end{tabular}

$S D$, Standard deviation; $V S D$, ventricular septal defect; $i R B B B$, incomplete right bundle branch block; $i L B B B$, incomplete left bundle branch block; $c R B B B$, complete right bundle branch block; $T R$, tricuspid regurgitation; $A R$, aortic regurgitation; $L V E F$, left ventricle ejection fraction; $L V$, left ventricle; $R V$, right ventricle.

4.5-mm perimembranous VSD with good result. ${ }^{14}$ The distribution of the size of the VSDs and implanted devices is shown in Figure 6. 5F delivery sheaths were used in 32 cases $(7.26 \%), 7 \mathrm{~F}$ in 366 cases $(82.99 \%)$, and $9 \mathrm{~F}$ in 43 cases $(9.75 \%)$. Most of the patients were discharged within 5 days.

There were no deaths or major complications in the device and surgical closure groups. The procedure and early postoperative results for both groups are summarized and compared in Table 2.

Pooling data from Table 2, the total operating time, postoperative ventilator support time, postoperative hospital stay, and complications in the device closure group were all significantly less than in the surgical closure group. The cost of hospitalization for the 2 groups was almost the same. Another obvious difference between the 2 groups was the number of blood transfusions. In the device closure group, only 16 patients ( $3.63 \%$ of 441 patients) received a blood transfusion as a result of difficult manipulation leading to a long operation time and extensive bleeding. In the surgical closure group, $100 \%$ of patients received transfusion of blood or blood products because of CPB.

\section{Follow-up Results}

There were no deaths during the hospital stay or throughout the follow-up period. Follow-up information was available for 426 patients $(96.60 \%)$ in the device closure group and 271 patients $(95.76 \%)$ in the surgical closure group, ranged from 6 to 78 months $(47.31 \pm$ 19.69 months) and 6 to 73 months (41.23 \pm 18.47 months), respectively; no severe complications occurred. There were fewer minor complications, such as device-related new trace to mild TR, residual shunt, right bundle branch block in the device closure group than in the surgical closure group (Table 3 ).

Pooling data from Table 3, except for 1 incomplete left bundle branch block in the device closure group, there were no severe complications, such as complete heart block, or more than mild valvular regurgitation in the device closure group or in the surgical closure group. Furthermore, during the follow-up period, we found that the incidence of minor complications, such as new tricuspid or aortic regurgitation, new incomplete right bundle branch block, or complete right bundle branch block, decreased. The ratio of residual shunting also decreased significantly, from $6.12 \%$ to $2.58 \%$ in the device group, compared with the surgical closure group, from $16.61 \%$ to $11.81 \%$. The left ventricular ejection fraction in all patients in the device closure group and the surgical closure group was normal.

\section{DISCUSSION}

We first reported our experience of transthoracic device closure of 11 cases of perimembranous VSD in $2007 .{ }^{1}$ Since then, we have used this new technique with promising 


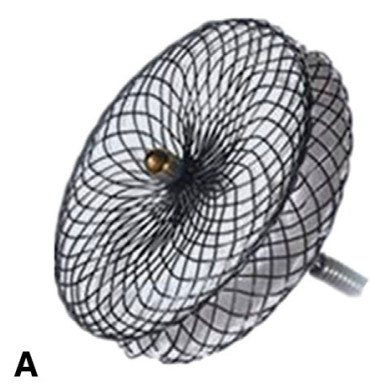

B
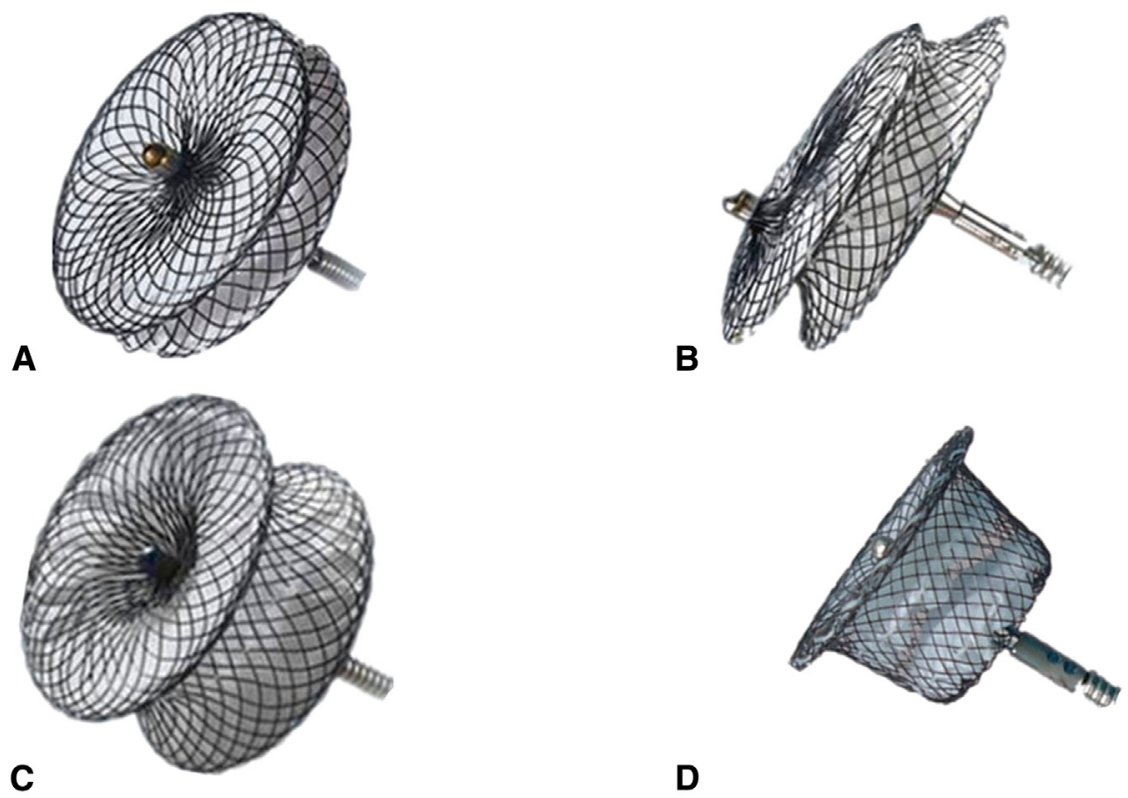

D

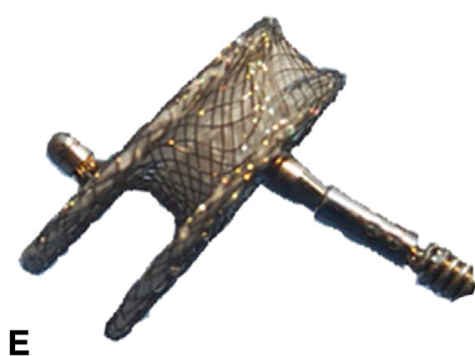

FIGURE 1. A, Perimembranous ventricular septal defect (VSD) concentric occluder (concentric); B, perimembranous VSD eccentric occluder (eccentric); C, muscular VSD occluder (muscular); D, patent ductus arteriosus occluder; E, saddlelike occluder for subarterial VSD.

results for more than 7 years. During this period, we have been improving this new technique, including designing new delivery systems and modifying devices to fit the anatomy of VSDs, in order to make the method simpler and suitable for younger patients, and more importantly to reduce the incidence of severe complications. $5,9,11,14$

Compared with conventional surgical closure and transcatheter device closure of VSDs, the advantages of MITDC seem to be obvious. In addition to less surgical trauma, no

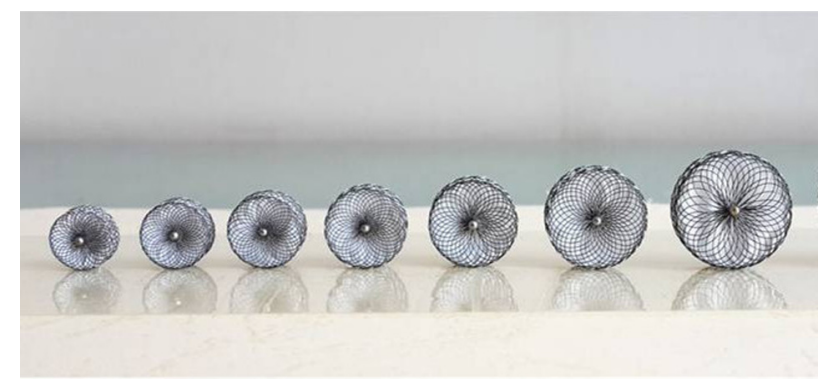

FIGURE 2. Concentric perimembranous ventricular septal defect occluders, $4 \mathrm{~mm}$ waist height (different waist diameters from left to right: $4 \mathrm{~mm}, 5 \mathrm{~mm}, 6 \mathrm{~mm}, 7 \mathrm{~mm}, 8 \mathrm{~mm}, 10 \mathrm{~mm}, 12 \mathrm{~mm}$ ). radiation, and no limitations due to the patient's age and body weight, the entire procedure can be done without the support of $\mathrm{CPB}$ and blood transfusion. In the transthoracic device closure group at our center, only 16 patients $(3.63 \%)$ required transfusion of blood products, and all these patients were treated in the early period. In the conventional surgical closure group, $100 \%$ of the patients required transfusion of blood products because of CPB priming. The more this technique can be performed, the

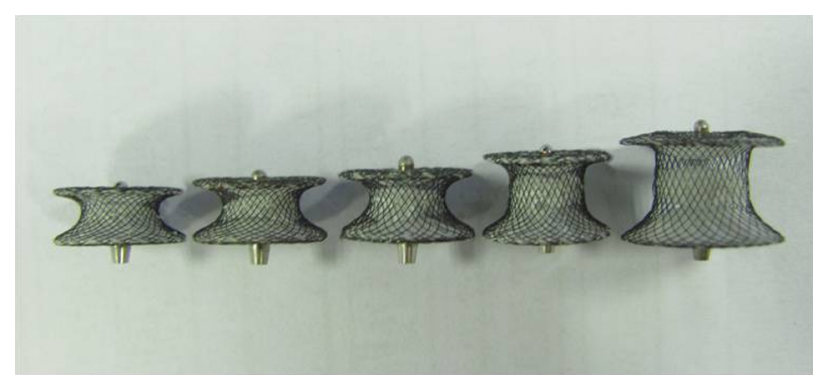

FIGURE 3. Concentric perimembranous ventricular septal defect occluders, $6 \mathrm{~mm}$ waist diameter (different waist heights from left to right: $3 \mathrm{~mm}, 4 \mathrm{~mm}, 5 \mathrm{~mm}, 6 \mathrm{~mm}, 7 \mathrm{~mm}$ ). 


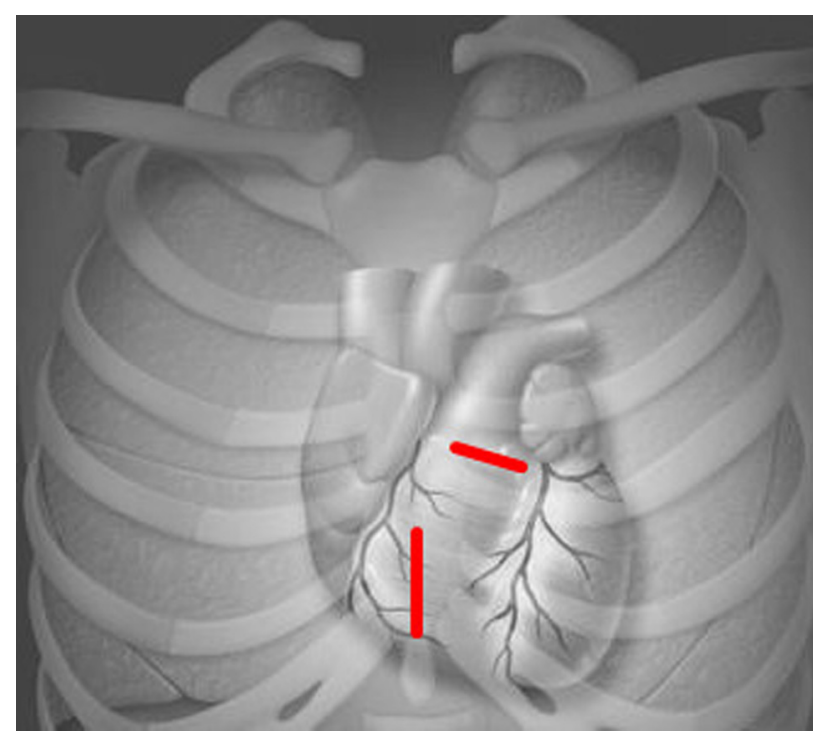

FIGURE 4. The incisions for minimally invasive transthoracic device closure of isolated ventricular septal defects.

more blood products can be saved, especailly in countries with blood shortages. This technique is not constrained by the patient's age and body weight as in the case of transcatheter closure. ${ }^{9}$ In our group, the youngest patient was only 3 months old and weighed $4.5 \mathrm{~kg}$. Whether very young patients with low body weight can be treated with this technique depends mainly on the operating pathway, the method, and the delivery set used. Unlike transcatheter device closure of VSDs through femoral vessels, which are constrained to patients more than 3 years old, transthoracic device closure can be done through a small sternum or intercostal incision that can completely avoid damage to peripheral vessels. In addition, the delivery system that we have designed and modified is short and easy to control in the operator's hands throughout the procedure. The simplicity and controllability of the delivery system make transthoracic device closure easier than with the long and complex delivery system used in transcatheter device closure under radiography.

Device-related late-onset severe arrhythmia, such as cAVB, is the hottest issue on which almost every cardiologist and pediatric cardiac surgeon focuses during percutaneous or perventricular closure of perimembranous VSDs. In our long-term clinical practice of intracardiac repair with $\mathrm{CPB}$ and percutaneous and perventricular device closure of perimembranous VSDs, we noticed that the incidence of cAVB during device closure of perimembranous VSDs between using Amplatzer occluders $(2.0 \%-20 \%)^{15-21}$ and using modified Chinese occluders
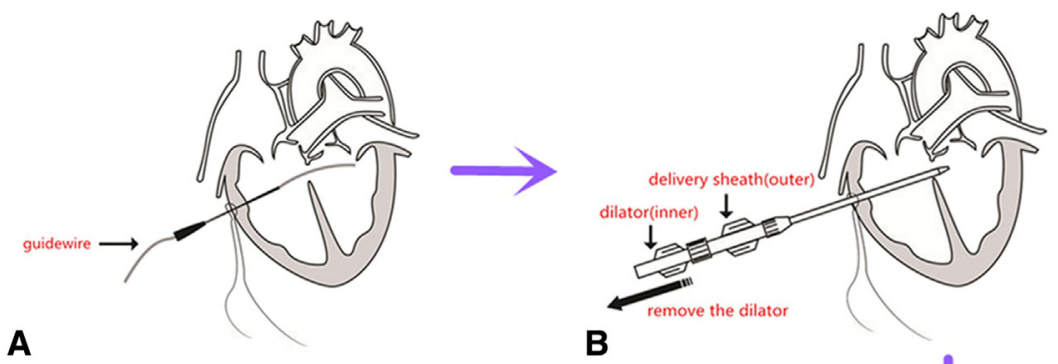

A

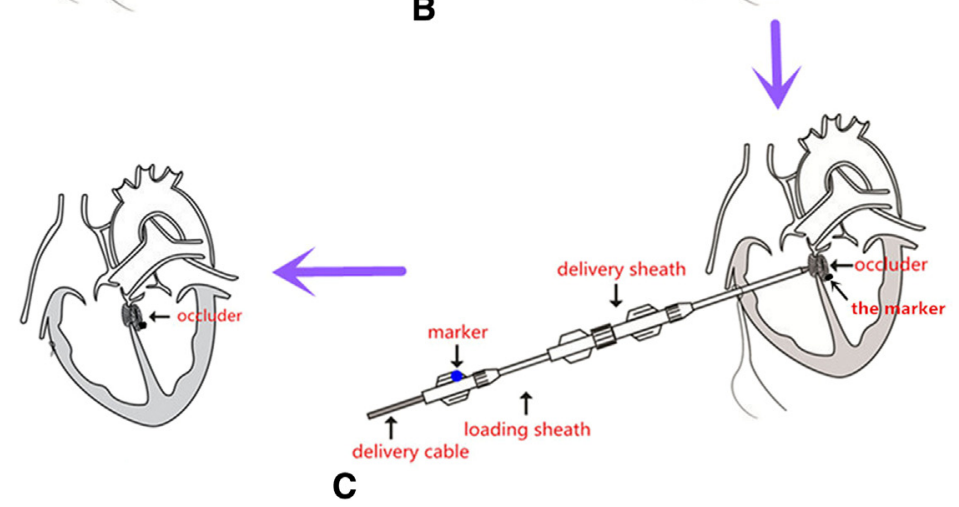

D

C

FIGURE 5. The steps involved in deployment of an eccentric occluder through the right ventricular free wall. A, A trocar was punctured into the right ventricle through the free wall and a $0.9-\mathrm{mm}(0.035$-inch) flexible guidewire was advanced through the trocar to pass the defect. B, The dilator and delivery sheath were advanced over the guidewire through the defect into the left ventricle, then the guidewire and the dilator were removed. $\mathrm{C}$, The loading sheath was introduced into the delivery sheath, and the device was advanced to the tip of the sheath. The left disk was deployed in the left ventricle, and adjusted by the platinum marker on the left disk, to make the hyperechoed mark correctly deviate from the aortic valve and face the apex, and then the loading sheath was withdrawn to deploy the waist and the right disk of the occluder. D, After complete assessment by transesophageal echocardiography for the absence of residual shunting, left and right ventricular outlet tract obstruction, valve interference and arrhythmia, the device was released. 
Distribution of the Size of the VSDs and Implanted Devices

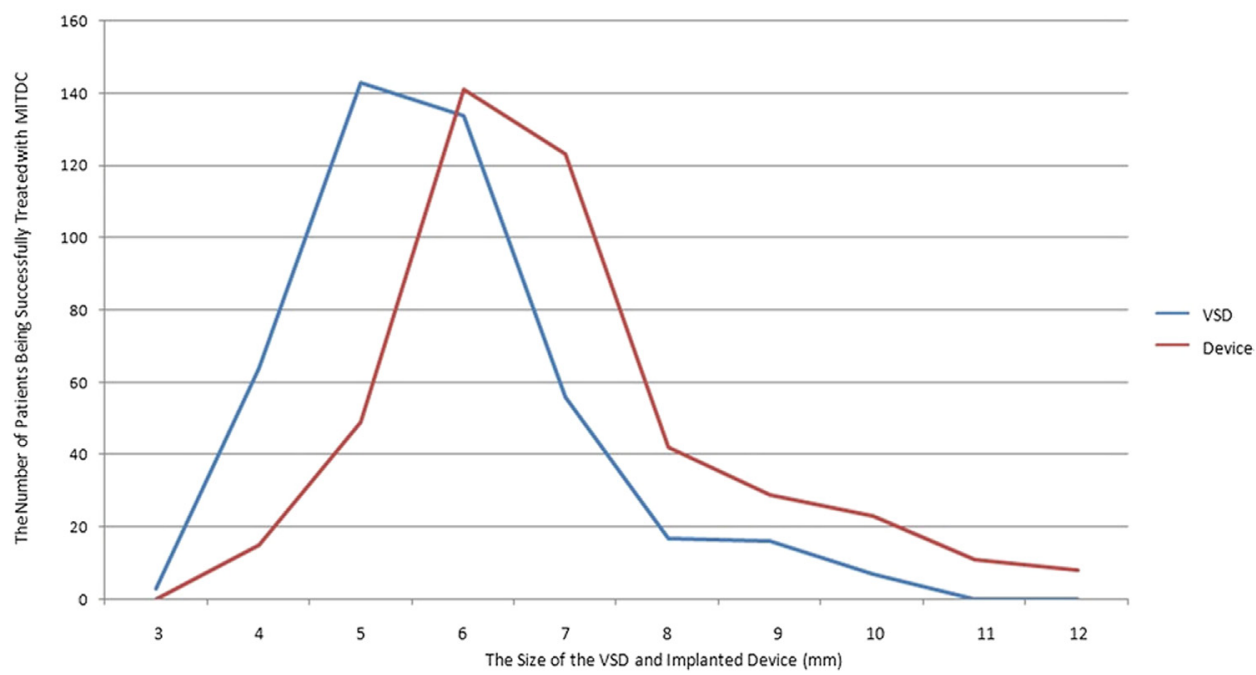

FIGURE 6. The distribution of the size of VSDs and implanted devices. MITDC, Minimally invasive transthoracic device closure; VSD, ventricular septal defect.

$(0 \%-1.3 \%)^{7,22-26}$ was significantly different. As cardiac surgeons face living hearts every day and with full understanding of the anatomy of perimembranous VSDs and adjacent structures, we believe that the occluder may play an important role in inducing cAVB. Since 2005, we have been working on modifying the occluders for perimembransous VSDs. In 2007, we began to use these modified occluders to close perimembranous VSDs transthoracically and achieved good early clinical results. During a 6-year follow-up period, there were no cases of complete heart block, except for 1 incomplete left bundle branch block. Compared with Amplazter eccentric occluders, the modified occluders we use in our group have 2 remarkable differences. First, the waist height of the occluder was enlarged from $3 \mathrm{~mm}$ to $7 \mathrm{~mm}$ in $1-\mathrm{mm}$ increments. The Amplatzer occluder has only 1 waist

TABLE 2. Procedure data and early postoperative results for patients undergoing transthoracic device or surgical closure of isolated ventricular septal defects

\begin{tabular}{|c|c|c|c|}
\hline Characteristic & Transthoracic device closure & Surgical closure & $P$ value \\
\hline Number & 441 & 283 & \\
\hline Total operating time, $\min \pm \mathrm{SD}$ (range) & $30.51 \pm 19.73(27-89)$ & $95.62 \pm 53.84(81-148)$ & .001 \\
\hline Blood transfusion, $\mathrm{n}(\%)$ & $16(3.63)$ & $283(100)$ & .000 \\
\hline Postoperative ventilator support time, $\mathrm{h} \pm \mathrm{SD}$ (range) & $1.12 \pm 1.55(0-2.5)$ & $8.31 \pm 11.59(0.5-42)$ & .041 \\
\hline Postoperative hospital stay, $\mathrm{d} \pm \mathrm{SD}$ (range) & $3.82 \pm 4.11(3-9)$ & $8.55 \pm 6.52(5-15)$ & .076 \\
\hline Cost of hospitalization, $1000 \mathrm{RMB} \pm \mathrm{SD}$ (range) & $28.97 \pm 10.24(22.45-31.43)$ & $31.56 \pm 25.38(25.56-48.12)$ & .521 \\
\hline \multicolumn{4}{|l|}{ Complications before discharge, $\mathrm{n}(\%)$} \\
\hline Hydropericardium & $18(4.08)$ & $26(9.19)$ & .005 \\
\hline Incision infection & $6(1.36)$ & $13(4.59)$ & .008 \\
\hline \multicolumn{4}{|l|}{ Electrocardiography, n (\%) } \\
\hline New iRBBB or cRBBB & $41(9.30)$ & $56(19.79)$ & .000 \\
\hline New iLBBB & 0 & 0 & \\
\hline cAVB & 0 & 0 & \\
\hline \multicolumn{4}{|l|}{ Echocardiography, n (\%) } \\
\hline $\begin{array}{l}\text { New trace to mild TR or aggravating to } \\
\text { mild-moderate TR compared with preoperatively }\end{array}$ & $26(5.90)$ & $53(18.73)$ & .000 \\
\hline Trace to mild AR & $7(1.59)$ & $12(4.24)$ & .029 \\
\hline \multicolumn{4}{|l|}{ Residual shunting } \\
\hline Trivial to small & $27(6.12)$ & $47(16.61)$ & .000 \\
\hline Moderate & 0 & 1 & .000 \\
\hline LVEF, $\% \pm$ SD (range) & $66.11 \pm 16.38(59-76)$ & $59.36 \pm 17.47(53-75)$ & .466 \\
\hline
\end{tabular}

$S D$, Standard deviation; $R M B$, renminbi; $i R B B B$, incomplete right bundle branch block; $C R B B B$, complete right bundle branch block; $i L B B B$, incomplete left bundle branch block; $c A V B$, complete atrioventricular block; $T R$, tricuspid regurgitation; $A R$, aortic regurgitation; $L V E F$, left ventricle ejection fraction. 
TABLE 3. Follow-up data of patients undergoing transthoracic device or surgical closure of isolated ventricular septal defects

\begin{tabular}{|c|c|c|c|}
\hline Characteristic & Transthoracic device closure & Surgical closure & $P$ value \\
\hline Follow-up time, mo $\pm \mathrm{SD}$ (range) & $47.31 \pm 19.69(6-78)$ & $41.23 \pm 18.47(6-73)$ & .883 \\
\hline Follow-up rate, $\mathrm{n}(\%)$ & $426(96.60)$ & $271(95.76)$ & .566 \\
\hline \multicolumn{4}{|l|}{ Complications during follow-up, $\mathrm{n}(\%)$} \\
\hline \multicolumn{4}{|l|}{ Electrocardiography } \\
\hline New iRBBB or cRBBB & $35(8.22)$ & $50(18.45)$ & .000 \\
\hline New iLBBB & $1(0.23)$ & 0 & .425 \\
\hline cAVB & 0 & 0 & \\
\hline \multicolumn{4}{|l|}{ Echocardiography } \\
\hline $\begin{array}{l}\text { New trace to mild TR or aggravating to mild-moderate } \\
\text { TR compared with preoperatively }\end{array}$ & $21(4.93)$ & $44(16.24)$ & .000 \\
\hline Trace to mild AR & $1(0.23)$ & $9(3.32)$ & .001 \\
\hline \multicolumn{4}{|l|}{ Residual shunting } \\
\hline Trivial to small & $11(2.58)$ & $32(11.81)$ & .000 \\
\hline Moderate & 0 & 0 & \\
\hline LVEF, $\% \pm$ SD (range) & $65.55 \pm 17.67(59-75)$ & $59.23 \pm 18.71(55-73)$ & .565 \\
\hline
\end{tabular}

$S D$, Standard deviation; $i R B B B$, incomplete right bundle branch block; $c R B B B$, complete right bundle branch block; $i L B B B$, incomplete left bundle branch block; $c A V B$, complete atrioventricular block; $T R$, tricuspid regurgitation; $A R$, aortic regurgitation; $L V E F$, left ventricle ejection fraction.

height specification of $1.5 \mathrm{~mm}$. From the viewpoint of the cardiac surgeon, properly increasing the waist height of the occluder, corresponding to the thickness of the IVS, can alleviate entrapment of the adjacent IVS, and theoretically minimize cAVB. Second, we designed a totally new concentric occluder that is more stable in vivo, and easier to deploy than the eccentric occluder. In most perimembranous VSDs, the distance between the defect and the aortic valve annulus is more than $2 \mathrm{~mm}$. So implanting a concentric occluder rarely impedes the motion of the aortic valve. In our transthoracic device closure group, we evaluate a perimembranous VSD and choose an occluder that not only corresponds to the size of the defect but also the thickness of the IVS around the defect, usually 3 to 5 $\mathrm{mm}$ thick in children varying with the body weight and age. It is important to avoid using an oversized occluder because progressive device flattening of an originally oversized device has been hypothesized as a mechanism for the development of cAVB. ${ }^{27}$ Furthermore, with the easily controllable delivery set, we often initially choose a smaller device, and if inappropriate, we can change to a second or third one in 1-mm increments or to another kind of occluder. These modifications to the occluder and delivery set have made it possible to provide personalized occluder selection and reduce the incidence of cAVB.

New valvular incompetence during the procedure and long-term postoperative valvular function are important issues in transthoracic device closure of VSDs. In our 441 cases of successful transthoracic closure, there was no device-related new aggravating or more than mild tricuspid or aortic regurgitation compared with preoperatively during the procedure or in the early postoperative period. The simplicity and controllability of this new technique can avoid damage to the valves and subvalvular structure under TEE real-time monitoring. In comparison, this is relatively more difficult to achieve in transcatheter interventions because of the long delivery pathway and obscure position from an indefinite radiologic angle in relation to the variations in the position of VSDs. In addition, cardiac surgeons are more familiar with the intracardiac anatomy and know how to avoid damage to myocardial and adjacent tissues during the procedure because they are doing intracardiac operations almost every day. During the long-term follow-up period, there was no more than mild valvular regurgitation and cardiac function was New York Heart Association class I in all patients with a normal left ventricle ejection fraction.

\section{Clinical Limitations}

Although the results of this study are encouraging, there are limitations to our study. First, no hemodynamic data were available because angiography was not performed in any of the patients; Second, this is only a 6-year followup from a single center; more experience and much longer follow-up results from multiple centers are mandatory to assess the long-term effectiveness and complications of this techinique. Third, this is a retrospective review not a prospective or laboratory-based study.

\section{CONCLUSIONS}

MITDC of VSDs on a beating heart is a safe and effective alternative to conventional treatments. The 6-year followup results are promising. The modification of occluders and the delivery set plays an important role in the good results. Much longer follow-up results and a prospective study are mandatory.

\section{References}

1. Xing QS, Zhuang ZY, Pan SL, Duan SH, Rong YB, Li SD. Minimally invasive transthoracic device closure of perimembranous ventricular septal defect with a 
newly designed delivery system in 11 children. Chin J Exp Surg. 2007;24: 1135-6.

2. Li F, Chen M, Qiu ZK, Lu J, Wu WH. A new minimally invasive technique to occlude ventricular septal defect using an occluder device. Ann Thorac Surg. 2008;85:1067-71.

3. Zeng XJ, Sun SQ, Chen XF, Ma XJ, Luo YH, Lim YP, et al. Device closure of perimembranous ventricular septal defects with a minimally invasive technique in 12 patients. Ann Thorac Surg. 2008;85:192-4.

4. Gan CP, An Q, Lin K, Tang H, Lui RC, Tao KY, et al. Perventricular device closure of ventricular septal defects: six months results in 30 young children. Ann Thorac Surg. 2008;86:142-6.

5. Xing QS, Pan SL, Zhuang ZY, Rong YB, Li SD, Cao Q, et al. Minimally invasive perventricular device closure of an isolated perimembranous ventricular septal defect with a newly designed delivery system: preliminary experience. $J$ Thorac Cardiovasc Surg. 2009;137:556-9.

6. Gan CP, Lin K, An Q, Tang H, Song HB, Lui RC, et al. Perventricular device closure of muscular ventricular septal defects on beating hearts: initial experience in eight children. J Thorac Cardiovasc Surg. 2009;137:929-33.

7. Xing Q, Pan S, An Q, Zhang Z, Li J, Li F, et al. Minimally invasive perventricular device closure of perimembranous ventricular septal defect without cardiopulmonary bypass: multicenter experience and mid-term follow-up. J Thorac Cardiovasc Surg. 2010;139:1409-15.

8. Tao K, Lin K, Shi Y, Song H, Lui RC, Gan C, et al. Perventricular device closure of perimembranous ventricular septal defects in 61 young children: early and midterm follow-up results. J Thorac Cardiovasc Surg. 2010;140: 864-70.

9. Xing Q, Wu Q, Pan S, Ren Y, Wan H. Transthoracic device closure of ventricular septal defects without cardiopulmonary bypass: experience in infants weighting less than 8 kg. Eur J Cardiothorac Surg. 2011;40:591-7.

10. Mo X, Zuo W, Ma Z, Wu K, Sun J, Peng W, et al. Hybrid procedure with cardiopulmonary bypass for muscular ventricular septal defects in children. Eur J Cardiothorac Surg. 2011;40:1203-6.

11. Pan S, Xing Q, Cao Q, Wang P, Duan S, Wu Q, et al. Perventricular device closure of doubly committed subarterial ventral septal defect through left anterior minithoracotomy on beating hearts. Ann Thorac Surg. 2012;94: 2070-5.

12. Schreiber C, Vogt M, Kühn A, Hörer J, Samprec J, Zhongyun Z, et al. Periventricular closure of perimembranous VSD: treatment option in selected patients. Thorac Cardiovasc Surg. 2012;60:78-80.

13. Omelchenko AY, Zhuang Z, Schreiber C, Gorbatykh YN, Arkhipov AN, Malakhova OY, et al. Surgical off-pump closure of perimembranous ventricular septal defects. Asian Cardiovasc Thorac Ann. 2014;22:31-5.

14. Wu Q, Xing Q, Chen Z, Pan S, Ren Y. Successful off-pump device closure of an isolated perimembraneous ventricular septal defect using a series of six occluders in a $5 \mathrm{~kg}$ infant via a minimally invasive approach. Eur Heart J. 2010;31:2659.

15. Dumitrescu A, Lane GK, Wilkinson JL, Goh TH, Penny DJ, Davis AM. Transcatheter closure of perimembranous ventricular septal defect. Heart. 2007;93:867.

16. Predescu D, Chaturvedi RR, Friedberg MK, Benson LN, Ozawa A, Lee KJ. Complete heart block associated with device closure of perimembranous ventricular septal defects. J Thorac Cardiovasc Surg. 2008;136:1223-8.

17. Carminati M, Butera G, Chessa M, De Giovanni J, Fisher G, Gewillig M, et al. Transcatheter closure of congenital ventricular septal defects: results of the European Registry. Eur Heart J. 2007;28:2361-8.

18. Butera G, Carminati M, Chessa M, Piazza L, Micheletti A, Negura DG, et al. Transcatheter closure of perimembranous ventricular septal defects: early and long-term results. J Am Coll Cardiol. 2007;50:1189-95.

19. Holzer R, de Giovanni J, Walsh KP, Tometzki A, Goh T, Hakim F, et al. Transcatheter closure of perimembranous ventricular septal defects using the amplatzer membranous VSD occluder: immediate and midterm results of an international registry. Catheter Cardiovasc Interv. 2006;68:620-8.

20. Fu YC, Bass J, Amin Z, Radtke W, Cheatham JP, Hellenbrand WE, et al. Transcatheter closure of perimembranous ventricular septal defects using the new Amplatzer membranous VSD occluder: results of the U.S. phase I trial. J Am Coll Cardiol. 2006;47:319-25.

21. Carminati M, Butera G, Chessa M, Drago M, Negura D, Piazza L. Transcatheter closure of congenital ventricular septal defect with Amplatzer septal occluders. Am J Cardiol. 2005;96:52L-8L.

22. Wang L, Cao S, Li J, Yang L, Liu Y, Ren J, et al. Transcatheter closure of congenital perimembranous ventricular septal defect in children using symmetric occluders: an 8-year multiinstitutional experience. Ann Thorac Surg. 2012;94: 592-8.

23. Li P, Zhao XX, Zheng X, Qin YW. Arrhythmias after transcatheter closure of perimembranous ventricular septal defects with a modified double-disk occluder: early and long-term results. Heart Vessels. 2012;27:405-10.

24. Zhou D, Pan W, Guan L, Ge J. Transcatheter closure of perimembranous and intracristal ventricular septal defects with the SHSMA occluder. Catheter Cardiovasc Interv. 2012;79:666-74

25. Qin Y, Chen J, Zhao X, Liao D, Mu R, Wang S, et al. Transcatheter closure of perimembranous ventricular septal defect using a modified double-disk occluder. Am J Cardiol. 2008;101:1781-6.

26. Jin Y, Han B, Zhang J, Zhuang J, Yan J, Wang Y. Postimplant complications with transcatheter closure of congenital perimembranous ventricular septal defects: a single-center, longitudinal study from 2002 to 2011. Catheter Cardiovasc Interv. 2013;81:666-73.

27. Butera G, Chessa M, Carminati M. Percutaneous closure of ventricular septal defects. Cardiol Young. 2007;17:243-53.

\section{Discussion}

Dr Robert Jaquiss (Durham, NC). Good morning, Dr Wu, I really enjoyed reading your paper and listening to your presentation. I will say that, having been at the meeting since Saturday, this is the most important paper for me as a congenital heart surgeon of all of the papers that I have heard.

During the meeting we have heard about many exotic lesions and many very challenging problems. In contrast, most congenital heart surgeons think of ventricular septal defects as neither exotic nor challenging. It is a problem that has been solved by our community. But the parents of our patients probably do not feel the same way. It is an important lesion for us to deal with, because it is the single most commonly done operation in our database, being about $7 \%$ of our operations. So VSD is a big deal numerically if not intellectually, and today you have shown us how I think we will approach this lesion in the future.

I will also confess that having followed the literature peripherally about transcatheter closure of perimembranous defects, I have not really thought of that technique as something that would replace what we do, because the literature about transcatheter/transvenous closure of ventricular septal defects consistently includes a significant incidence of heart block of at least several percent. In comparison with surgical closure of VSD with cardiopulmonary bypass, where the incidence of heart block is nearly zero, that few percent is a big number. Furthermore, percutaneous transcatheter closure has not been applicable to the children in the age range that we operate on. In the North American experience in the Society of Thoracic Surgeons database, the typical patient is about 6 months old and much less than $10 \mathrm{~kg}$. The transvenous devices are really only applicable to children who weigh $15 \mathrm{~kg}$.

What you have shown us today is a device that is applicable to children in the size range that we operate on, placed with a technique that offers our patients and our families no transfusion, no cardiopulmonary bypass, and now for the first time no heart block. I was struck by your slide that compared the contemporaneous surgical results from your institution with patients who were essentially the same. Your device and technique was not only as good as open surgery; it was actually better. You had less atrioventricular valve regurgitation in the tricuspid position, less aortic regurgitation, and fewer residual defects. So in every 
way you have shown us a real improvement, and I congratulate you for that.

In the interest of time I have 2 fairly simple questions.

First, why do you think your device, compared with the Amplatzer device with which there is much more experience and much more heart block, produces so little conduction disturbance? That is my first question. So why no heart block?

Second, how low do you think the body weight that your technique and device could be used in would be? What is the smallest child who can have this procedure done?

Again, congratulations and thank you.

Dr Wu. Thank you. The second question; I will first answer that. The lowest body weight in our group was $4.5 \mathrm{~kg}$ at 3 months of age.

And the first question, complete atrioventricular block is the hottest issue with regard to device closure of VSDs. There was no complete atrioventricular block in our group. We think this is mainly because of the modified occluders we use. Compared with the Amplatzer VSD occluder, the modified occluder we use has 2 remarkable differences: first, the waist height of the occluder was enlarged from $3 \mathrm{~mm}$ to $7 \mathrm{~mm}$ in $1-\mathrm{mm}$ increments.
The Amplatzer occluder has only 1 waist height $(1.5 \mathrm{~mm})$. From the viewpoint of a cardiac surgeon, properly increasing the waist height to correspond with the thickness of the intraventricular septum alleviates compression of the adjacent intraventricular septum and theoretically minimizes atrioventricular block.

Second, we designed a totally new concentric perimembranous VSD occluder. This kind of occluder may be more stable in the heart and is much easier to deploy. And in most perimembranous VSDs, the distance between the defect and the aortic valve annulus is more than $2 \mathrm{~mm}$, so implanting the concentric occluder rarely interferes with the motion of the aortic valve and the concentric occluder does not have a protruding edge on the left disk which faces the apex after being deployed and then compresses the left side of the intraventricular septum where we know the conductive tissue is passing through.

Avoiding an oversized occluder is another very important point because progressive device flattening of originally oversized device has been hypothesized as a mechanism for the development of complete atrioventricular block.

\title{
EDITORIAL COMMENTARY
}

\section{"The times they are a-changin""}

\author{
Winfield J. Wells, MD
}

See related article on pages 257-65.

\section{The times they are a-changin' \\ —Robert Allen Zimmerman (aka Bob Dylan), 1963}

Although there have been major improvements in perioperative care, cardiopulmonary bypass, myocardial protection, hemodynamic monitoring, and anesthetic management, the fundamentals of ventricular septal defect (VSD) closure have changed little since the pioneering work done nearly 60 years ago in Minnesota. ${ }^{1}$ We are still using circulatory support with its obligate inflammatory response, opening the heart, and sewing a patch in place to close the defect while

\footnotetext{
From the Children's Hospital of Los Angeles and Division of Thoracic Surgery, Keck School of Medicine, University of Southern California, Los Angeles, Calif. Disclosures: Author has nothing to disclose with regard to commercial support. Received for publication Sept 23, 2014; accepted for publication Sept 26, 2014; available ahead of print Oct 25, 2014.

Address for reprints: Winfield J. Wells, MD, Division of Thoracic Surgery, Keck School of Medicine, University of Southern California, Los Angeles, CA 90027 (E-mail: wwells@chla.usc.edu).

J Thorac Cardiovasc Surg 2015;149:265-6

$0022-5223 / \$ 36.00$

Copyright (C) 2015 by The American Association for Thoracic Surgery http://dx.doi.org/10.1016/j.jtcvs.2014.09.109
}

accruing ischemic time to the myocardium. The use of blood products is also common in infants, a large portion of the patient population.

This report by Xing and colleagues ${ }^{2}$ from Qingdao University on the northeast coast of China is a harbinger of what may be a paradigm shift in the way we manage some patients with a VSD. Based on earlier experiences, the concept of VSD closure with a catheter-delivered occluder is likely to trigger a negative response, primarily because of the incidence of heart block. ${ }^{3}$ However the development of the modified device as described by the Qingdao team merits reconsideration of this technique.

The strengths of the report are the large number of patients $(n=458)$ and the fact that $97 \%$ of them were followed up for an average of 4 years by 2 dedicated physicians using a standardized protocol. The outstanding results speak for themselves and the authors seem to have mitigated the complications associated with earlier occluders. Among those scheduled for the minimally invasive transthoracic device procedure, $96 \%$ had a successful closure of their VSD. There was no early or late mortality. There was not a single incident of complete heart block, only a $0.23 \%$ incidence of trace or mild aortic insufficiency, and less than $5 \%$ incidence of trace or mild 